\title{
EL COSTO DE CRECER EN LA PYME
}

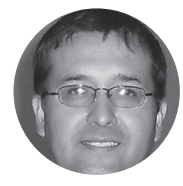

\author{
RICARDO W. TRUJILLO
}

- Profesor de Fundamentos de las Finanzas

Carrera de Administración y Finanzas

Facultad de Negocios, UPC

Las pequeñas y medianas empresas (pymes) están en todo momento buscando recursos de corto plazo, sobre todo en temas tan puntuales como la consolidación de una deuda, el pago a proveedores, el financiamiento de lotes de producción. El contexto puede ser multivariado o variopinto como dirían algunos autores de novelas, pero lo real y concreto es que las pymes necesitan financiamiento. Desde el umbral de mi humilde cuartel de escritos y memorias, traigo al frente el tema del financiamiento, no porque sea algo recurrente o de moda, sino sobre todo porque hoy en día y más que antes, la banca está dispuesta a asumir mayores riesgos siempre y cuando su costo de oportunidad sea bien compensado. Pero he aquí el dilema (mi perspectiva es del lado del prestatario, es decir, de quien asume el costo financiero de la deuda), ¿es correcto endeudarse asumiendo sobrecostos financieros? ¿Acaso no nos cuentan desde el colegio, pasando por el instituto y la universidad, que uno debe endeudarse al menor costo financiero posible? ¿Qué ocurre con la banca nacional que, en los últimos 26 años, no ha podido desarrollar nuevos o mejores instrumentos financieros para el sector que más recursos demanda en el corto plazo? ¿O es que se ha agotado la creatividad del sector, limitándonos simplemente a asumir créditos de manera indiscriminada y a los mayores costos financieros? Creemos que aún estamos a tiempo y hoy es posible plantear nuevos instrumentos financieros de corto plazo que permitan a la gran base de pequeñas y medianas empresas, tomar deuda por debajo de su costo de oportunidad, lo cual coadyuvaría a que muchas empresas puedan saltar la valla para competir a otro nivel, mejorando sus márgenes de ganancia versus la gran industria.

....TRAIGO AL FRENTE EL TEMA DEL FINANCIAMIENTO, NO PORQUE SEA ALGO RECURRENTE O DE MODA, SINO SOBRE TOOO PORQUE HOY EN DÍA Y MÁS QUE ANTES, LA BANCA ESTÁ DISPUESTA A ASUMIR MAYORES RIESGOS SIEMPRE Y CUANDO SU COSTO DE OPORTUNIDAD SEA BIEN COMPENSADO.

¿Cuántas veces hemos escuchado decir o hablar sobre el bajo o poco nivel de formalización de las empresas del segmento pyme, lo cual muchas veces limita el acceso a los créditos en la banca tradicional? Pues tenemos que decir que este ya no es más un argumento que valide la regla: “como la gran mayoría de empresas pyme no está formalizada, entonces no le queda más que tomar posiciones en corto con sobrecostos financieros exagerados. Esta situación se ve trastocada puesto que mientras la recaudación de los Medianos y Pequeños Contribuyentes ha aumentado en 106\% entre los años 2010 y 2015, la de los Principales Contribuyentes creció en $27 \%$, lo cual es un indicador de ampliación de la base tributaria" (Sunat asesoró a 450,000 pymes para evitar cobranzas coactivas de tributos, 2016).

Esto es fundamental porque echa por tierra este clásico supuesto de acceso al mercado financiero por parte de las pymes. Según la SUNAT, a través del desarrollo de su programa de gestión inductiva, se ha logrado contactar a cerca de 450,000 pymes, mediante lo cual se ha logrado reducir la cobranza coactiva. Esto demuestra que actualmente, a pesar de la coyuntura negativa en cuanto al contexto económico mundial, las pymes tienen y pueden generar flujos de caja futuro, los cuales les permite cubrir deuda no solo con la SUNAT a nivel tributario, sino también con el sistema financiero (Morosidad bancaria se redujo y llegó a 2.58\% en setiembre, 2015). Cuando los bancos otorgan un crédito no solo se preguntan si uno o cualquier pyme podrá pagar, sino sobre todo si querrá pagar, caso en que está clarísimo que por lo menos al cierre del 2015, muchas de las pymes sí podían y querían pagar sus deudas. Pero ésta situación no explica por qué la banca tradicional grava con sobrecostos a las pymes, que es el sector más frágil y con mayor índices de empleabilidad de nuestra economía.

\section{BARRERAS DE ACCESO, GARANTÍAS SOBRE LAS gARANTÍAS}

\footnotetext{
En la Doctrina apreciamos la Estructura de un Sistema / Esquema de Garantías, que desde el punto de vista orgánico constituye un apreciado andamiaje coherente, que explica la integración de los elementos de un sistema / esquema de garantía, a través de su finalidad, esto es, combatir la pobreza, desde que es un hecho real la existencia de la dificultad de acceso al crédito por carencia o insuficiencia de garantías del sector de la micro y pequeña empresa. Es por demás interesante entender esta simple relación entre la garantía y el fondo/préstamo a desembolsar entre la institución financiera y el cliente (Coquis, s.f.)
}

Como bien lo manifiesta Coquis, la naturaleza de la garantía es respaldar el crédito, pero lo crítico en el sector pyme estriba en que estas garantías son nulas e inexistentes en muchos de los casos. 
Situación compleja y real, que funge de barrera al momento de la gestión crediticia. Ante ello, las opciones u oportunidades de acceso al crédito se ven más que limitadas y de alguna manera perversa y trágica. Las pequeñas y medianas empresas se ven arrastradas a un mar enorme y abundante de instituciones financieras o crediticias como las cajas rurales, Edpyme y otras de esta naturaleza, que si bien es cierto son flexibles en cuanto a exigencias crediticias, suben sus costos financieros por el mayor riesgo asumido ante las operaciones crediticias con las pymes. Generando con ello que las pequeñas y medianas empresas en nuestra economía, cedan parte del valor generado por ellas.

En una conversación sostenida con el ingeniero Carlos Oré Peñaranda, fundador de OPE Contratistas Generales SAC y actualmente consultor del sector construcción, nos relata cómo muchas veces al inicio de la vida de su organización, al no recibir el respaldo de la banca formal, con el otorgamiento de cartas fianzas y/o pagares, se vio forzado a recurrir al otro grupo de empresas financieras o crediticias como las cajas rurales, Edpyme y otras que cobraban sobrecostos financieros. Al no tener acceso a otra variedad o tipo de instrumentos financieros de manera natural, indica, tenía que aceptar esas condiciones para seguir trabajando en su rubro, puesto que en una industria tan competitiva como la de la construcción, muchas veces es mejor estar en el campo de acción que no estarlo; y esto a veces implica sacrificar parte de su margen de ganancia. En corto, que otros se apropien del valor que tú generas.

En base a lo comentado anteriormente podemos decir, como afirma Coquis:

... muchos estudiosos en el Tema de Sistemas de Garantía en España, Portugal, Colombia, Argentina y Perú permanente y sostenidamente expresan en los distintos Foros Iberoamericanos que el Sistema / Esquema de Garantía es una "herramienta básica y fundamental" de desarrollo de las Micro y Pequeñas Empresas (MYPE) e inserción en el circuito financiero formal. Los Sistemas de Garantía reducen los riesgos potenciales de una operación de crédito para la institución financiera y a los clientes les permite tener acceso a créditos más favorables (Coquis, s.f.)

Si bien se espera que las garantías reduzcan el riesgo de una operación crediticia, el tema en el caso de las pequeñas y medianas empresas, es que por su naturaleza, estas garantías son de difícil obtención, entonces se hace necesario y fundamental establecer un sistema de garantías que trabaje para el otorgamiento de estas a favor de las pymes, situación coyuntural en la cual organismos, como FOGAPI, no tengan el impacto que se espera. A partir de esto, sería interesante analizar si desde el inicio de sus operaciones, el FOGAPI ha impactado positivamente o negativamente en el sector pyme; tal vez sería éste un interesante tema de estudio posterior.

\section{NUEVOS INSTRUMENTOS}

Finalmente, estamos convencidos que mientras no se desarrollen nuevos instrumentos financieros que

\section{...EN EL CASO DE LAS PEQUEÑAS Y MEDIANAS EMPRESAS, ES QUE POR SU NATURALEZA, ESTAS GARANTÍAS SON DE DIFÍCIL OBTENCIÓN, ENTONCES SE HACE NECESARIO Y FUNDAMENTAL ESTABLECER UN SISTEMA DE GARANTÍAS QUE TRABAJE PARA EL OTORGAMIENTO DE ÉSTAS A FAVOR DE LAS PYMES.}

permitan un mayor acceso al crédito para nuestras pymes, acompañados de fondos de garantías, no se mejorarán los costos de este tipo de operaciones para las pyme.

Instrumentos como la letras en cobranza libre, letras en descuento, factoring, pagarés y/o cartas fianzas se usan con mucha frecuencia, pero no en los volúmenes y cantidades necesarias. Si se hiciera un análisis sobre dónde están orientadas principalmente estas herramientas, estamos seguros, de que muchas de estas no están impactando directamente en el sector pyme en la actualidad, sino en la mediana empresa.

A partir de lo revisado en nuestro documento creemos que sería más que interesante usar en el sistema actual el cheque con pago diferido como una herramienta complementaria para la pyme; pero si se articulara un mecanismo que permita a las pymes tener en los bancos una especie de línea de crédito en garantías a manera de sobregiro a tasas competitivas o como líneas de crédito revolvente se podría dar más liquidez al sector, ayudando a dinamizar la producción y a la generación de empleo.

Actualmente, los bancos otorgan líneas de créditos revolventes, a tasas elevadas, en desmedro de los márgenes de ganancias de la pyme. Creemos que en la medida en que se fortalezca y empoderen a las pymes, no solo a través de la formalización, sino sobre todo en el establecimiento de garantías, éstas podrían contar con un mayor acceso al crédito. Para ello, el FOGAPI puede y debería rediseñar sus políticas de establecimiento de garantías para que el sector se dinamice en mayor medida.

\section{REFERENCIAS}

Coquis, E. (s.f.). Consideraciones sobre el sistema / esquema de garantías para el acceso al financiamiento. Fondo de Garantía para Prestamos a la Pequeña Industria. Recuperado a partir de: https://www.fogapi.com.pe/ assets/consideraciones-sobre-el-sistema-esquema-degarant\%C3\%ADas-para-el-acceso-al-financiamiento2.pdf

Morosidad bancaria se redujo y llegó a 2.58\% en setiembre. (2015, 21 de octubre). Diario Gestión. Recuperado a partir de: http://gestion.pe/mercados/morosidad-bancaria-se-redujoy-llego-258-setiembre-2146116

Sunat asesoró a 450,000 pymes para evitar cobranzas coactivas de tributos. (2016, 9 de marzo). Diario Gestión. Recuperado a partir de: http://gestion.pe/economia/ sunatasesoro-450000-pymes-evitar-cobranzascoactivastributos-2156060 